\title{
PENERAPAN PEWARNA ALAMI BIJI ALPUKAT PADA KAIN KATUN
}

\author{
Sumarli1) \\ 1)STKIP Singkawang, Singkawang, Kalimantan Barat, Indonesia \\ Corresponding author : sumarliphysics@gmail.com \\ E-mail : sumarliphysics@gmail.com
}

Diterima 01 November 2021, Disetujui 09 November 2021

\begin{abstract}
ABSTRAK
Biji alpukat dapat diekstrak menjadi zat warna alam karena mengandung senyawa tanin yang dapat menimbulkan warna cokelat atau kecokelatan. Kelemahan zat warna alam dalam proses pewarnaan tekstil yakni memiliki ketahanan luntur yang rendah. Oleh karena itu, pada proses pencelupan bahan tekstil dengan zat warna alam dibutuhkan proses fiksasi agar warna memiliki ketahanan luntur yang baik. Pewarna alami dari biji alpukat telah diterapkan pada kain katun. Ketahanan luntur pewarna alami telah diuji dengan memvariasikan massa tawas sebagai bahan fiksasi terhadap nilai perubahan intensitas cahaya pada air residu hasil pencucian kain katun. Perlakuan menggunakan variasi massa tawas $10 \mathrm{~g}$ hingga $60 \mathrm{~g}$ dengan waktu pencelupan selama 10 menit. Desain penelitian terdiri dari ekstraksi biji alpukat sebagai sumber zat warna alam, mordanting dan pencelupan kain katun ke dalam larutan zat warna, fiksasi kain katun, dan pengujian ketahanan luntur warna pada kain katun menggunakan luxmeter setelah pencucian menggunakan air biasa dan air deterjen. Hasil penelitian menunjukkan bahwa sampel yang menggunakan massa tawas $60 \mathrm{~g}$ menghasilkan tingkat kelunturan warna paling kecil dengan nilai perubahan intensitas cahaya 9,58lux pada hasil pencucian dengan air biasa dan 3,11lux pada hasil pencucian dengan air deterjen. Semakin tinggi massa tawas yang digunakan sebagai bahan fiksasi pada kain katun, maka pewarna alami biji alpukat memiliki ketahanan luntur yang semakin baik. Penggunaan sampel tawas $60 \mathrm{~g}$ sebagai bahan fiksasi efektif dalam menjaga ketahanan luntur pewarna alami biji alpukat pada kain katun.
\end{abstract}

Kata kunci: Biji Alpukat; Kain Katun; Pewarna Alami; Tawas.

\begin{abstract}
Avocado seeds could be extracted into natural dyes because they contained of tannin. Tannin as a dyes substances would cause brown or brownish color. The weakness of natural dyes in the textile dyeing process that has a low fade resistance. Therefore, the dyeing process of textile materials with natural dyes were needed fixation process in order that color had a well fade resistance. The natural dyes from avocado seeds had been applicated on cotton textile. The fade resistance of natural dyes had been tested by varying the mass of $\mathrm{Al}_{2}\left(\mathrm{SO}_{4}\right)_{3}$ as a fixation to the value of light intensity difference on the residue water of the cotton textile washing. The treatment used the mass variation of $10 \mathrm{~g}$ to $60 \mathrm{~g}$ $\mathrm{Al}_{2}\left(\mathrm{SO}_{4}\right)_{3}$ by dyeing for 10 minutes. The study design consisted of avocado seeds extraction as a source of natural dyes, mordanting of cotton textile, dyeing of cotton textile in a dye solution, fixation of cotton textile and test the fade resistance of natural dyes on cotton textile using a luxmeter after washing by water and detergent solution. The results showed that the sample used a mass of $60 \mathrm{~g} \mathrm{Al}_{2}\left(\mathrm{SO}_{4}\right)_{3}$ produced the smallest color fade degree with the value of light intensity difference on the residue water was 9.58lux of washing by water and 3.11lux of washing by detergent solution. The higher mass of $\mathrm{Al}_{2}\left(\mathrm{SO}_{4}\right)_{3}$ was used as fixation on cotton textile, the natural dyes of avocado seeds had a better fade resistance. The using of $60 \mathrm{~g} \mathrm{Al}_{2}\left(\mathrm{SO}_{4}\right)_{3}$ sample as a fixation material was effective for kept the fade resistance of natural dyes from avocado seeds on cotton textile.
\end{abstract}

Keywords: Avocado Seeds; Cotton Textile; Natural Dyes.

\section{PENDAHULUAN}

Zat warna merupakan salah satu zat aditif yang ditambahkan pada suatu produk. Penggunaan zat warna sudah semakin luas terutama dalam makanan, minuman maupun tekstil, karena warna memberikan daya tarik bagi konsumen (Winarti, Sarofa, \& Anggrahini,
2008). Berdasarkan sumbernya, zat warna dibagi menjadi dua jenis, yaitu pewarna alami dan pewarna sintetis (Cahyadi, 2008). Penggunaan pewarna sintetis memiliki beberapa kerugian, diantaranya membahayakan kesehatan manusia dan secara tidak langsung meracuni lingkungan 
sehingga perlu adanya penelitian dan pengembangan inovasi pewarna yang bersumber dari alam (Tocharman, 2009). Pewarna alami umumnya aman dan tidak menimbulkan efek samping bagi tubuh (Kurniastuti \& Susanti, 2009).

Tanaman alpukat (Persea americana Mill.) merupakan tanaman yang berasal dari dataran tinggi Amerika Tengah dan memiliki banyak varietas yang tersebar di seluruh dunia (Lopez, 2002; Dabas dkk., 2011). Umumnya jika mengonsumsi buah alpukat, bagian bijinya dianggap tidak bermanfaat sehingga dibuang begitu saja. Padahal, bagian biji alpukat kalau mendapatkan penanganan lebih lanjut dapat dikembangkan menjadi zat warna alami untuk pewarnaan tekstil. Sejauh ini penelitian terhadap biji alpukat masih pada tahap ekstraksi biji alpukat sebagai sumber potensial pewarna alami pada makanan (Dabas dkk., 2011). Selain itu, ekstraksi zat saponin dari biji alpukat juga dimanfaatkan sebagai bahan tambahan dalam pembuatan deterjen (Damayanti, 2015). Ekstraksi minyak dari biji alpukat juga dapat dimanfaatkan sebagai bahan baku biodiesel (Prasetyowati, Pratiwi, \& Fera, 2010).

Biji alpukat mengandung senyawa polifenol, triterpenoid, flavonoid, tanin, kuinon monoterpenoid dan seskuiterpenoid (Dabas dkk., 2011; Damayanti, 2015; Prasetyowati, Pratiwi, \& Fera, 2010; Leite dkk., 2009; Soong \& Barlow, 2004). Tanin, sebagai zat pewarna akan menimbulkan warna cokelat atau kecokelatan (Dabas dkk., 2011; Yi \& Cho, 2008; Prayitno, Kismolo, \& Nurimaniwati, 2003; Lestari, Wijana, \& Putri, 2013). Senyawa tanin tidak larut dalam pelarut non polar, seperti eter, kloroform, dan benzena, tetapi mudah larut dalam air, dioksan, aseton, dan alkohol serta sedikit larut dalam etil asetat (Prayitno, Kismolo, \& Nurimaniwati, 2003; Lestari, Wijana, \& Putri, 2013; Handayani \& Maulana, 2013). Pengambilan tanin dilakukan dengan proses ekstraksi (Dabas dkk., 2011; Prayitno, Kismolo, \& Nurimaniwati, 2003; Lestari, Wijana, \& Putri, 2013; Handayani \& Maulana, 2013; Pansera dkk., 2004). Sampai saat ini metode pemisahan yang paling sering digunakan adalah metode ekstraksi dengan pelarut karena efektifitas dan efisiensinya dibandingkan metode pemisahan yang lain (Lestari, Wijana, \& Putri, 2013; Handayani \& Maulana, 2013; Pansera dkk., 2004; Syaifuddin, 2011). Penelitian sebelumnya telah dilakukan ekstraksi tanin pada daun alpukat sebagai pewarna alami dengan warna yang dihasilkan berupa warna cokelat (Lestari, Wijana, \& Putri, 2013).

Proses pewarnaan pada tekstil secara sederhana meliputi mordanting, pewarnaan, fiksasi, dan pengeringan (Fitrihana, 2007; Rosyida, 2015). Proses mordanting ini dimaksudkan untuk meningkatkan daya tarik zat warna alami terhadap tekstil serta berguna untuk menghasilkan kerataan dan ketajaman warna yang baik (Fitrihana, 2007; Rosyida, 2015; Manurung, 2012). Pada proses pencelupan bahan tekstil dengan zat warna alam dibutuhkan proses fiksasi (fixer) yaitu proses penguncian warna setelah bahan dicelup dengan zat warna alam agar warna memiliki ketahanan luntur yang baik (Fitrihana, 2007; Rosyida, 2015; Manurung, 2012).

Bahan tekstil yang diwarnai dengan zat warna alam adalah bahan-bahan yang berasal dari serat alam contohnya sutera, wol dan kapas (katun) (Fitrihana, 2007; Rosyida, 2015; Manurung, 2012). Bahan-bahan dari serat sintetis seperti polyester, nilon dan lainnya tidak memiliki afinitas atau daya tarik terhadap zat warna alam sehingga bahan-bahan ini sulit terwarnai dengan zat warna alam (Fitrihana, 2007). Selama ini proses pewarnaan tekstil dengan zat warna alam masih memiliki beberapa kelemahan, diantaranya selain pilihan warnanya terbatas, zat warna alam juga memiliki ketahanan luntur yang masih rendah pada kain katun. Oleh karena itu, perlu dilakukan uji ketahanan luntur pewarna alami biji alpukat pada kain katun dengan memvariasikan massa tawas $\left(\mathrm{Al}_{2}\left(\mathrm{SO}_{4}\right)_{3}\right)$ sebagai bahan fiksasi.

\section{METODE PENELITIAN}

Alat-alat yang digunakan dalam penelitian antara lain pisau, gunting, neraca digital, gelas beker, pemanas atau kompor, dan luxmeter. Bahan-bahan yang digunakan antara lain biji alpukat, air, tawas, sabun netral (sunlight), deterjen cair, soda abu dan kain katun. Variabel bebas pada penelitian ini adalah variasi massa tawas sebagai bahan fiksasi, sedangkan variabel terikat adalah hasil pengukuran intensitas cahaya pada air residu hasil pencucian kain katun.

Proses ekstraksi. Biji alpukat dicuci hingga bersih dan dijemur hingga kering. Biji alpukat dipotong menjadi ukuran kecil-kecil (ekstrak) dan ditimbang sebanyak $50 \mathrm{~g}$ untuk setiap sampel. Ekstrak dididihkan dengan perbandingan massa ekstrak dan air sebesar 1:10 (500ml air) hingga volume air menjadi setengahnya yakni $250 \mathrm{ml}$. Larutan hasil proses ekstraksi kemudian disaring untuk mendapatkan larutan zat warna alam.

Proses mordanting. Kain katun sebagai sampel dipotong sebanyak enam helai dengan ukuran $(10 \times 10) \mathrm{cm}^{2}$ dan diberi nomor urut sesuai dengan variasi massa tawas yakni nomor 1-6 untuk massa tawas (10-60)g. Kain uji 
direndam dalam larutan $2 \mathrm{~g} / \mathrm{t}$ sabun netral (sunlight) selama 2 jam. Larutan yang terdiri dari $8 \mathrm{~g}$ tawas dan $2 \mathrm{~g}$ soda abu dididihkan dalam 1 lt air. Kain uji dimasukkan ke dalam larutan tersebut dan direbus selama satu jam. Selanjutnya api dimatikan dan kain uji dibiarkan terendam dalam larutan selama $24 \mathrm{jam}$. Kain uji diangkat kemudian dibilas dan dianginanginkan hingga kering.

Proses pencelupan. Kain uji yang telah dimordanting dimasukkan ke dalam larutan zat warna alam dan dibiarkan terendam selama 30 menit. Kain uji diangkat kemudian dianginanginkan hingga kering.

Proses fiksasi. Larutan tawas dibuat dengan memvariasikan massa tawas $10 \mathrm{~g}$ hingga $60 \mathrm{~g}$ dalam setiap $500 \mathrm{ml}$ air. Larutan diendapkan dan diambil larutan beningnya. Kain uji dimasukkan ke dalam larutan fixer dan direndam selama 10 menit. Kain uji diangkat kemudian dibilas dan diangin-anginkan hingga kering.

Uji ketahanan luntur warna pada kain katun melalui pencucian menggunakan $500 \mathrm{ml}$ air biasa dan $500 \mathrm{ml}$ air deterjen yang telah dilarutkan $1 \mathrm{~g}$ deterjen cair. Intensitas cahaya pada air biasa dan air deterjen sebelum pencucian diukur menggunakan luxmeter. Kain uji direndam dalam air biasa dan air deterjen selama 30 menit. Selanjutnya dilakukan pengukuran intensitas cahaya pada air residu hasil pencucian.

Luxmeter adalah alat yang digunakan untuk mengukur besar intensitas penerangan di suatu tempat. Semakin jauh jarak antara sumber cahaya ke sensor, maka semakin kecil nilai yang ditunjukkan luxmeter (Gunadhi, 2002). Besar intensitas penerangan dari sumber cahaya $\left(E_{\mathrm{p}}\right)$ yang mengenai suatu permukaan memiliki satuan lux atau lumen $/ \mathrm{m}^{2}$ seperti terlihat pada persamaan (1).

$$
E_{p}=\frac{I}{r^{2}}
$$

Persamaan (1) menunjukkan bahwa intensitas penerangan sebanding dengan intensitas cahaya dan berbanding terbalik dengan kuadrat jarak sumber cahaya dari titik pengamatan (Rosita dkk., 2014). Pengukuran besarnya intensitas penerangan dari lampu floerescent berjarak sangat dekat (kurang dari $5 \mathrm{~cm})$, maka kuadrat jarak ini bernilai kecil dan dapat diabaikan. Oleh karena itu, dapat dibuat sebuah pendekatan bahwa besarnya intensitas penerangan yang terukur oleh luxmeter dianggap sebagai intensitas cahaya.

Hasil pengukuran intensitas cahaya pada air residu hasil pencucian kemudian dihitung selisihnya dengan menggunakan persamaan (2).

$$
\Delta I=I_{0}-I
$$

dengan $\Delta I$ adalah nilai perubahan intensitas cahaya; $I_{0}$ adalah besar intensitas cahaya awal (sebelum pencucian); dan $I$ adalah besar intensitas cahaya akhir (setelah pencucian).

\section{HASIL DAN PEMBAHASAN}

Berdasarkan eksperimen yang telah dilakukan, maka dihasilkan warna cokelat atau kecokelatan pada kain katun setelah dilakukan pencelupan ke dalam larutan pewarna alami biji alpukat (Gambar 1a). Kain katun kemudian mengalami perubahan warna menjadi cokelat muda setelah difiksasi ke dalam larutan tawas (Gambar 1b). Perubahan warna yang dihasilkan dari larutan fixer disebabkan terjadinya reaksi antara tanin dengan logam $\mathrm{Al}^{3+}$ pada tawas yang membentuk garam kompleks sehingga menghasilkan warna cokelat yang lebih muda pada kain katun (Handayani \& Maulana, 2013). Variasi massa tawas sebagai bahan fiksasi tidak memberikan pengaruh yang signifikan terhadap perubahan warna pada kain katun (Gambar 1b). Warna cokelat yang ditampilkan pada kain katun menunjukkan bahwa zat tanin yang dihasilkan biji alpukat berpotensi sebagai sumber pewarna alami pada kain katun (Dabas dkk., 2011; Yi \& Cho, 2008; Prayitno, Kismolo, \& Nurimaniwati, 2003; Lestari, Wijana, \& Putri, 2013).

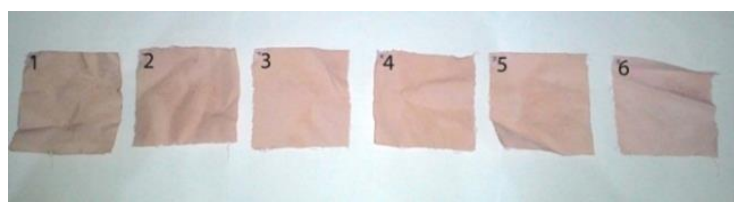

(a)

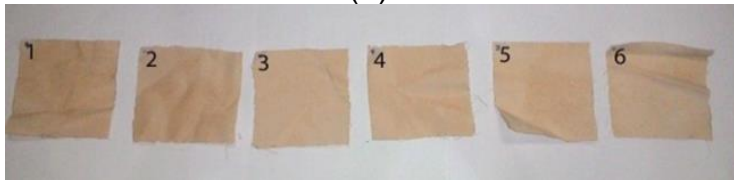

(b)

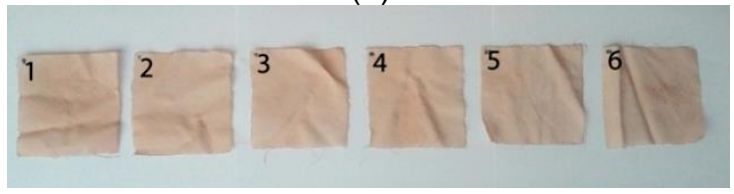

(c)

Gambar 1. Warna Cokelat pada Kain Katun:

(a) Setelah Pencelupan Zat Warna, (b) Setelah

Pencelupan ke dalam Larutan Fixer, (c) Setelah Pencucian

Secara visual warna pada kain katun mengalami kelunturan yang tidak signifikan setelah dilakukan pencucian (Gambar 1c). Hasil uji ketahanan luntur pewarna alami biji alpukat pada kain katun diperoleh melalui hasil pengukuran intensitas cahaya pada air residu hasil pencucian kain katun menggunakan luxmeter. Sumber cahaya yang digunakan 
berasal dari lampu floerescent bertegangan 100V. Data hasil pengukuran intensitas cahaya disajikan pada Tabel 1 .

Tabel 1. Nilai Perubahan Intensitas Cahaya pada Air Residu Hasil Pencucian Kain Katun

\begin{tabular}{|c|c|c|c|c|c|c|c|c|}
\hline \multicolumn{3}{|c|}{ Massa Tawas (g) } & 10 & 20 & 30 & 40 & 50 & 60 \\
\hline \multirow{6}{*}{$\begin{array}{l}\text { Intensitas Cahaya } \\
\text { (Iux) }\end{array}$} & \multirow{3}{*}{ Air Biasa } & $I_{0}$ & \multicolumn{6}{|c|}{49,60} \\
\hline & & $I$ & 33,18 & 35,12 & 36,85 & 37,95 & 39,20 & 40,02 \\
\hline & & $\Delta I$ & 16,42 & 14,48 & 12,75 & 11,65 & 10,40 & 9,58 \\
\hline & \multirow{3}{*}{ Air Deterjen } & $I_{0}$ & \multicolumn{6}{|c|}{34,95} \\
\hline & & $I$ & 21,69 & 22,38 & 23,28 & 25,33 & 24,28 & 31,84 \\
\hline & & $\Delta I$ & 13,26 & 12,57 & 11,67 & 9,62 & 10,67 & 3,11 \\
\hline
\end{tabular}

Data pada Tabel 1 dihitung menggunakan persamaan (1). Grafik hubungan antara variasi massa tawas sebagai bahan fiksasi terhadap nilai perubahan intensitas cahaya pada air residu hasil pencucian kain katun ditampilkan pada Gambar 2.

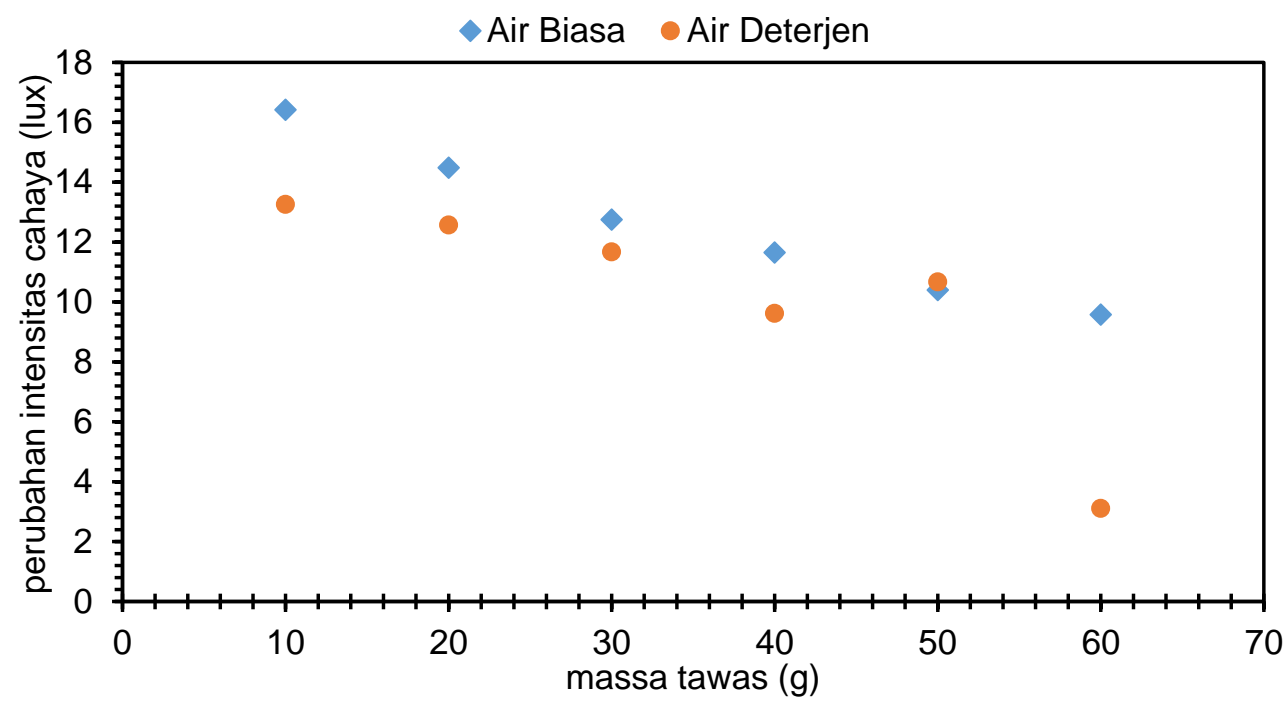

Gambar 2. Grafik Pengaruh Massa Tawas terhadap Perubahan Intensitas Cahaya pada Air Residu Setelah Pencucian dengan Air Biasa dan Air Deterjen

Berdasarkan Gambar 2, terjadi penurunan nilai perubahan intensitas cahaya pada air residu seiring dengan peningkatan massa tawas sebagai bahan fiksasi baik pada air biasa maupun air deterjen. Secara umum, nilai perubahan intensitas cahaya pada air deterjen lebih rendah daripada air biasa (Gambar 2). Hal ini disebabkan intensitas cahaya yang melalui medium air deterjen sebagian besar dipantulkan dan diserap oleh molekul-molekul deterjen yang terurai dalam air sehingga intensitas cahaya yang diteruskan dari medium tersebut semakin berkurang (Rosita dkk., 2014).

Tawas dengan massa $60 \mathrm{~g}$ menghasilkan tingkat kelunturan warna paling kecil dengan nilai perubahan intensitas cahaya 9,58lux pada air biasa dan 3,11lux pada air deterjen (Gambar 2). Hal ini mengindikasikan bahwa massa tawas sebagai bahan fiksasi (pengunci warna) berpengaruh terhadap ketahanan luntur warna pada kain katun.
Penyebabnya adalah ikatan yang terbentuk antara zat tanin dan serat berupa ikatan hidrogen, yaitu ikatan sekunder yang terbentuk oleh atom hidrogen pada gugus hidroksil serat kapas yang mengadakan ikatan fisik dengan zat tanin yang merupakan kromofor/gugus pembawa warna pada biji alpukat (Rosyida, 2015; Manurung, 2012). Ikatan hidrogen pada umumnya lebih lemah daripada ikatan kovalen. Kehadiran bahan fiksasi menyebabkan terjadinya ikatan kovalen antara logam $\mathrm{Al}^{3+}$ dari tawas dan gugus hidroksil dari serat kain katun sehingga mampu menguatkan ikatan antara zat tanin dan serat kain katun (Manurung, 2012).

Semakin banyak massa tawas yang digunakan sebagai bahan pengunci warna, maka semakin kuat ikatan kimia yang terjadi antara tanin dan serat kain sehingga semakin sedikit zat tanin yang terlepas dari serat saat dilakukan pencucian. Pelepasan zat tanin ini ditandai dengan adanya perbedaan nilai intensitas cahaya pada air sebelum dan setelah 
dilakukan pencucian, baik pada air biasa maupun air deterjen.

\section{SIMPULAN}

Berdasarkan hasil penelitian dapat disimpulkan bahwa penggunaan sampel tawas $60 \mathrm{~g}$ sebagai bahan fiksasi efektif dalam menjaga ketahanan luntur pewarna alami biji alpukat pada kain katun. Semakin tinggi massa tawas yang digunakan sebagai bahan fiksasi pada kain katun, maka pewarna alami biji alpukat memiliki ketahanan luntur yang semakin baik.

\section{DAFTAR RUJUKAN}

Cahyadi, W. (2008). Analisis dan Aspek Kesehatan: Bahan Tambahan Pangan. Jakarta: Bumi Aksara.

Dabas, D., Elias, R.J., Lambert, J. D., \& Ziegler, G.R. (2011). A Colored Avocado Seed Extract as A Potential Natural Colorant. Journal of Food Science, 76(9), C1335C1341.

Damayanti, H.M., N. A. Praditia, R. W. Murti, M. Ahmad, dan N. Widyaningrum. (2015). Ekstrak Biji Alpukat sebagai Pembusa Deterjen: Pemanfaatan Potensi Bahan Alam dan Menekan Biaya Produksi. Prosiding Seminar Nasional Peluang Herbal sebagai Alternatif Medicine, Universitas Wahid Hasyim, Semarang, Indonesia, 92-98.

Fitrihana, N. (2007). Teknik Eksplorasi Zat Pewarna Alam dari Tanaman di Sekitar Kita untuk Pencelupan Bahan Tekstil. Majalah Wuny, LPM UNY, 1-8.

Gunadhi, A. (2002). Perancangan dan Implementasi Alat Ukur Cahaya Sederhana. Proceedings Komputer dan Sistem Intelijen, Universitas Gunadarma, Jakarta, 49-58.

Handayani, P.A. \& Maulana, I. (2013). Pewarna Alami Batik dari Kulit Soga Tingi (Ceriops tagal) dengan Metode Ekstraksi. Jurnal Bahan Alam Terbarukan, 2(2), 1-6.

Kurniastuti, F. \& Susanti, E.L.D. (2009). Pembuatan Zat Warna Alami Tekstil dari Biji Buah Mahkota Dewa. Tugas Akhir. Universitas Negeri Surakarta.

Leite, J.J.G., Brito, E.H.S., Cordeiro, R.A., Brilhante, R.S.N., Sidrim, J.J.C., Bertini, L.M., de Morais, S.M., \& Rocha, M.F.G. (2009). Chemical Composition, Toxicity, and Larvicidal and Antifungal Activities of Persea americana (Avocado) Seed Extracts. Revista da Sociedade Brasileira de Medicina Tropical, 42(2), 110-113.
Lestari, P., Wijana, S., \& Putri, W.I. (2013). Ekstraksi Tanin dari Daun Alpukat (Persea americana Mill.) sebagai Pewarna Alami (Kajian Proporsi Pelarut dan Waktu Ekstraksi)", Penelitian Jurusan Teknologi Industri Pertanian, Universitas Brawijaya, 1-7.

Lopez, V.M.G. (2002). Fruit Characterization of High Oil Contect Avocado Varieties. Scientia Agricola, 59(2), 403-406.

Manurung, M. (2012). Aplikasi Kulit Buah Manggis (Garcinia Mangostana L.) sebagai Pewarna Alami pada Kain Katun secara Pre-Mordanting. Jurnal Kimia, 6(2), 183-190.

Pansera, M.R., lob, G.A., Atti-Santos, A.C., Rossato, M., Atti-Serafini, L., \& Cassel, E. (2004). Extraction of Tannin by Acacia Mearnsii with Supercritical Fluids. Journal Internasional Brazilian Archives of BiologyAnd Technology, 47(6), 995-998.

Prasetyowati, Pratiwi, R., \& Fera, O.T. (2010). Pengambilan Minyak Biji Alpukat (Persea americana mill) dengan Metode Ekstraksi. Jurnal Teknik Kimia, 17(2), 16-24.

Prayitno, Kismolo, E., \& Nurimaniwati. (2003). Proses Ekstraksi Bahan Pewarna Alam dari Limbah Kayu Mahoni. Prosiding Pertemuan dan Presentasi Ilmiah Penelitian Dasar IImu Pengetahuan dan Teknologi Nuklir, BATAN, Yogyakarta, Indonesia, 207-213.

Rosita, N., Susanto, Putro, A.S.P., Bangun, R.Br., Yulianto, A., \& Aji, M.P. (2014). Sintesis Pigmen Alami Daun Tanaman Andong (Cordyline fruticosa $L$.) sebagai Pewarna Batik dan Analisis Sifat Optiknya. Jurnal Fisika, 4(2), 88-91.

Rosyida, A. (2015). Pengaruh Variasi pH dan Fiksasi pada Pewarnaan Kain Kapas dengan Zat Warna Alam dari Kayu Nangka Terhadap Kualitas Hasil Pewarnaannya. Prosiding seminar Nasional $4^{\text {th }}$ UNS SME's Summit \& Awards, Universitas Negeri Surakarta, Surakarta, 101-112.

Soong, Y.Y. \& Barlow, P.J. (2004). Antioxidant Activity and Phenolic Content of Selected Fruit Seeds. Food Chemistry, 88, 411-417.

Syaifuddin, M. (2011). Pengaruh Aerasi pada Sianidasi Emas dari Batuan Mineral. Tugas Akhir. Institut Teknologi Sepuluh Nopember.

Tocharman, M. (2009). Eksperimen Pewarna Alami dari Bahan Tumbuhan yang Ramah Lingkungan sebagai Alternatif 
untuk Pewarnaan Kain Batik. Skripsi. Universitas Pendidikan Indonesia.

Winarti, S., Sarofa, U., \& Anggrahini, D. (2008). Ekstraksi dan Stabilitas Warna Ubi Jalar Ungu (Ipomoea batatas L.) sebagai Pewarna Alami. Jurnal Teknik Kimia, 3(1), 207-213.

Yi, E. \& Cho, J.Y. (2008). Color Analysis of Natural Colorant-Dyed Fabrics. Color Research and Application, 33(2), 148157. 